\title{
Concrete Electrical Resistivity at Varied Water, Chloride Contents and Porosity - Experiment, Modelling \& Application
}

\author{
Yu Wang ${ }^{1, *}$, Hayder Oleiwi², Nan Xiang ${ }^{3}$ \\ ${ }^{1}$ School of Science, Engineering \& Environment, University of Salford, Manchester M5 4WT, UK \\ ${ }^{2}$ College of Engineering, University of Thi-Qar, Nasiriyah, Iraq \\ ${ }^{3}$ School of Civil Engineering, Chongqing Jiao Tong University, Chongqing 400074, China \\ *Corresponding author: E-mail: y.wang@salford.ac.uk; Tel: (+44) (0) 1612956822
}

DOI: 10.5185/amlett.2020.071536

Understanding and characterizing the relationship between the electrical resistivity and the major influencing factors of the concrete have been all the time a topical research in relation to structural durability. This paper reports an experimental study on the influences of water and chloride contents, and porosity on the electrical resistivity of the Portland cement concrete. The results indicate that the electrical resistivity has a strong correlation with the water and chloride contents in concrete. A new characteristic model has been proposed to represent the correlation. The proposed model has been implemented into a numerical modelling case study of cathodic protection for reinforced concrete structure in saline environment.

\section{Introduction}

Electrical resistivity of concrete plays an important role in the assessment of the condition of concrete structures and the state of corrosion protection for reinforcement [1-4]. Concrete resistivity as parameter has also been employed to indicate concrete deterioration state. Water in concrete plays the media for free ions transfer, such as chloride. For the reason, the total water content, the chloride concentration in pore water, and concrete pore structure are the three factors of the primary interest in the concern of concrete electrical resistivity. Understanding the relationship between concrete resistivity and these factors receives a long standing attention in the research of concrete durability $[\mathbf{5 , 6}]$.

Cathodic protection $(\mathrm{CP})$ has been proved the most effective technique for concrete reinforcement corrosion protection [7]. Meanwhile numerical modelling has become an important tool in CP design and operation analysis [810]. The modelling of the $\mathrm{CP}$ process operated on reinforced concrete structures is generally based on the Nernst-Planck equation and the Ohm's law [11]. To solve the governing equations, concrete electrical resistivity as a material parameter is required. On the other hand, concrete resistivity directly influences the corrosion process of steel reinforcements by controlling the corrosion potential and the corrosive current [12]. As result, to accurate estimate the concrete resistivity at varied environmental conditions is important for the assessment of the $\mathrm{CP}$ protection for the reinforcement in concrete.

Although a large number of experimental work have already been reported on concrete electrical resistivity $[\mathbf{1 3 , 1 4}]$, the characterization of the relationship between the electrical resistivity and concrete condition is still open to discussion. There hasn't had a universal model which is able to describe the coupled effects of all these influencing factors and in general applicable for a wide range of applications. As an effort to address the challenge, this paper reports an experimental study and mathematical characterisation work on concrete electrical resistivity to investigate three major influencing factors, including, water saturation, chloride content and porosity, and a case study to use the characteristic model in a numerical modelling of $\mathrm{CP}$ for a reinforcement concrete structure exposed to costal conditions.

\section{Experiments}

Locally produced Portland limestone cement, CEM II/ALL conforming to the British standard BS EN 197-1: 2011, was used for the concrete mixes at $390 \mathrm{~kg} / \mathrm{m}^{3}$. Natural sand of the maximum size of $4.75 \mathrm{~mm}$ and a relative density of 2.47 was used for the fine aggregate at $580 \mathrm{~kg} / \mathrm{m}^{3}$. The coarse aggregate was the limestone of $10 \mathrm{~mm}$ maximum size and 2.49 specific gravity and used at $1125 \mathrm{~kg} / \mathrm{m}^{3}$. The mix of concrete followed the British standard, BS 1881125:2013.

Four different chloride contents were prepared by adding $\mathrm{NaCl}$ in the mix water. The added chloride contents are $0,1.5,3$ and $4.5 \%$ of the cement mass, respectively. Three water to cement ratios (w/c) were used for each chloride content. They are $0.4,0.5$ and 0.6 , respectively. All the casted concrete samples were cured by submerged in the water of the same chloride content as that used for their mixes. Such fully saturated curing method aims for an even distribution of chloride in the concrete and therefore makes 


\section{Advanced Materials Letters www.vbripress.com/aml}

the test results more reliable. The actual chloride content (both total and free) in the concrete specimens were specifically measured after curing following the standards (ASTM C1218/C1218M \& ASTM C1152/C1152M). For each mix, three specimens were prepared for each property measuring, and the final result took the average of the triplicate measurements.

Concrete cubes of the size of $100 \mathrm{~mm} \times 100 \mathrm{~mm} \times 100 \mathrm{~mm}$ were cast as shown in the Fig. 1. Both internal and external electrode methods, as illustrated in Fig. 2, were adopted in order to compare the reliability of measurements, and two different electrode materials were compared, they were carbon fibre fabric and copper plates, respectively.
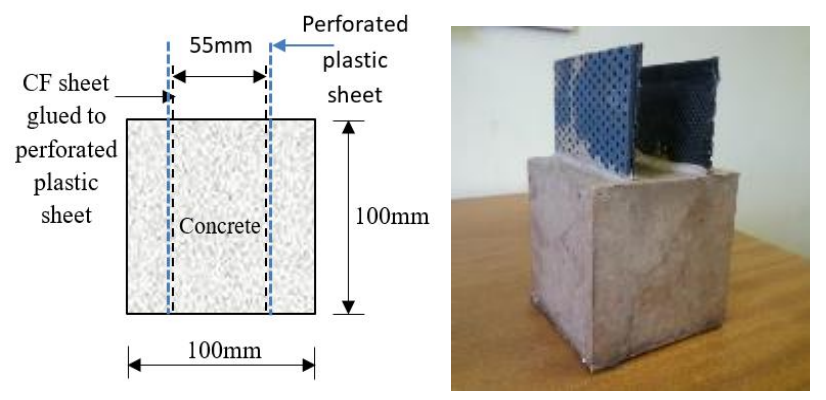

Fig. 1. The design of the specimens of internal electrodes.
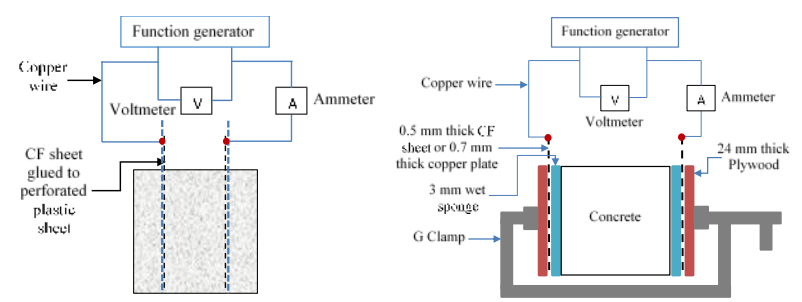

Fig. 2. Internal and external electrodes.

In the test, fully saturated samples were measured at first. Later, to obtain the condition of different uniformly distributed water contents, all the samples of different chloride contents were put in environmental chambers of three controlled relatively humidity $(\mathrm{RH})$ values, which were $35 \%, 60 \%$ and $80 \%$, respectively. These samples were kept in the chambers of a controlled temperature of $21^{\circ} \mathrm{C}$ for 3.5 5 months' time until no weight change observed $(<0.001 \mathrm{~g})$ and then they were taken out to measure the electrical resistivity. After the measurement of the electrical resistivity at three different water contents corresponding to the three controlled RH values, all these samples at last were put in an oven of a controlled temperature of $100 \pm 5^{\circ} \mathrm{C}$ until reached a stable dry condition, and then were measured again for their electrical resistivity. The water content for each condition was measured using the weighing method.

The influence of applied AC frequency on the electrical resistivity measurement was evaluated in a range from $1 \mathrm{~Hz}$ to $10 \mathrm{kHz}$. In theory, the most suitable frequency should produce the lowest resistance [15]. In addition, the influence of the applied voltage value has also been investigated in a range of $1 \sim 6 \mathrm{~V}$ in an interval of $1 \mathrm{~V}$. The identified optimum frequency and voltage were later used for all the tests in this study.

\section{Results and discussion}

It was noticed that chloride content has a neglectable effect on the porosity (the ratio of fully saturated water volume to concrete volume) of the prepared samples when compared with water to cement ratio. Table 1 gives out the measure average porosity of all the concrete samples using the same w/c.

Table 1. The measured average porosity of samples.

\begin{tabular}{cccc}
\hline w/c & 0.4 & 0.5 & 0.6 \\
Porosity & 0.16 & 0.19 & 0.21 \\
\hline
\end{tabular}

Fig. 3 shows the influence of the AC frequency on the electrical resistance measured on the chloride free specimens and the specimens of the highest $\mathrm{Cl}$ content $(3 \%$ $\mathrm{NaCl}$ ). It can be seen that using carbon fibre internal electrodes, the variation of the measurements in the range of the $\mathrm{AC}$ frequencies is the smallest almost unchanged particularly for the mix of $3 \% \mathrm{NaCl}$. This can be explained due to the improved contact between the electrode and concrete which helps to reduce the extra polarization at their interfaces. Meanwhile $\mathrm{Cl}$ ions also reduce the interfacial polarization as well.
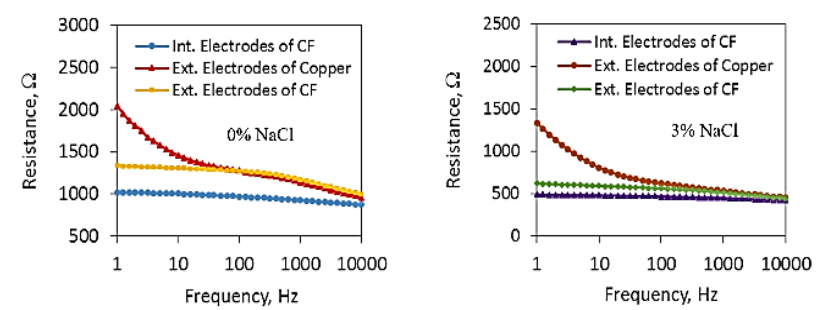

Fig. 3. Influence of AC frequency.

Fig. 4 shows the measured water contents (water weight percentage in term of the weight of concrete sample) exposed to different RH conditions.
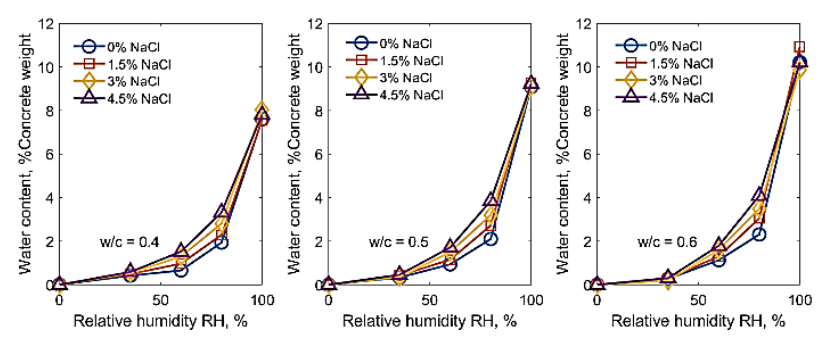

Fig. 4. Water content vs RH.

Fig. 5 shows the measured electrical resistivity of chloride free concrete at different water contents and their corresponding pore water saturation degrees (the ratio of the water content at unsaturated states to the water content at fully saturated state), respectively. It can be been noticed that concrete electrical resistivity decreases sharply and nonlinearly with the increase of the water content. There is a single unique relationship between electrical resistivity and water content, which looks independent from the 


\section{Advanced Materials Letters www.vbripress.com/aml}

porosity. However, the porosity effect on electrical resistivity can be clearly demonstrated in the relationship between the electrical resistivity and the pore water saturation degree.
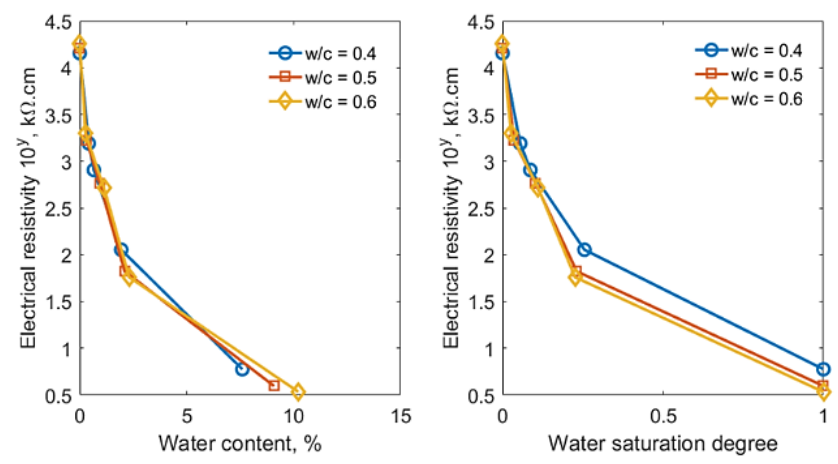

Fig. 5. Water effect on the resistivity of chloride free specimens.

Fig. 6 shows the measured electrical resistivity of the concrete samples of different chloride contents at fully saturated state. It shows that the electrical resistivity decreases considerably with the increase of chloride content. At the high w/c or porosity, the electrical resistivity decreases almost linearly with the increase of chloride content. As the w/c or porosity decreases, this relationship gradually deviates from linearity. The porosity or w/c influence becomes much smaller when the free chloride content is beyond the $0.35 \%$.
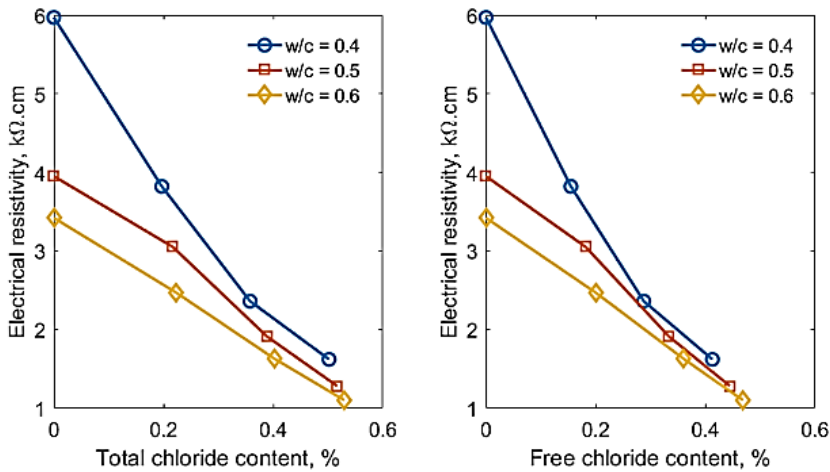

Fig. 6. Chloride effect on the resistivity of saturated specimens.

\section{Data characterization}

Fundamentally, the pore water in concrete acts as the solely media for electrical conductivity. In addition to absolute water quantity, the water distribution in concrete pore network plays an important role in deciding the electrical conductivity as well. The water distribution or configuration at varied pore water saturation degree depends upon the pore size distribution. As a result, the influence of water content on electrical conductivity or resistivity is intrinsically related to concrete pore size distribution. On the ground, we adopted a water retention characteristic model ever proposed [16], and revised it to characterise the relationship between electrical resistivity and concrete water saturation:

$$
\rho_{c}=f_{0}+\rho_{0}\left[\exp \left(\alpha S_{w}\right)+\exp \left(\beta\left(1-S_{w}\right)\right)\right]
$$

where $\rho_{c}$ is concrete resistivity, $S_{w}$ is pore water saturation, $f_{0}, \rho_{0}, \alpha$ and $\beta$ are four constant parameters.

To characterise the coupled effect of the water and chloride contents on concrete electrical resistivity, an exponential form function was employed to weigh the Eq. (1) and generates a model below [17]:

$$
\rho_{c}=\exp \left(a C_{C l}^{b}\right)\left(f_{0}+\rho_{0}\left[\exp \left(\alpha S_{w}\right)+\exp \left(\beta\left(1-S_{w}\right)\right)\right]\right)
$$

where $C_{C l}$ is the chloride content in concrete; $a$ and $b$ are two new constant parameters. Fig. 7 shows the results using the Eq. (2) to fit all the experimental data obtained before. Both visual inspection and fitting statistics have showed that Eq. (2) presents a good representation for all the experimental measurements.
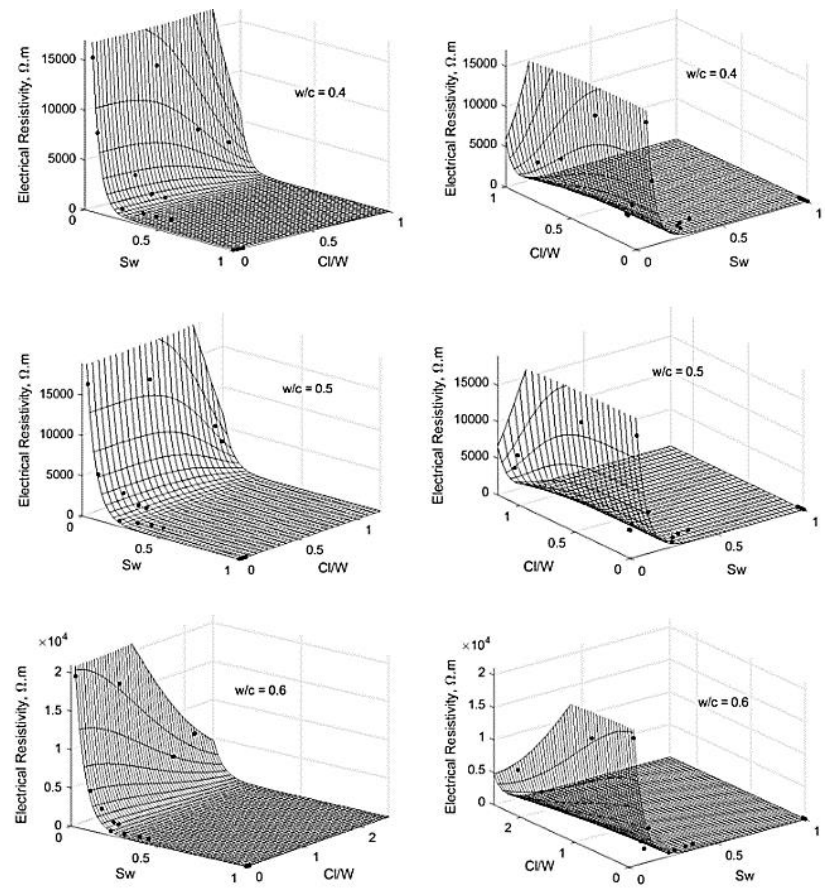

Fig. 7. Modelling the coupling effect of water and chloride contents on concrete resistivity.

\section{Application in cathodic protection modelling}

The transportation model takes account of the most major mechanisms involved $[\mathbf{1 1 , 1 8}]$. In terms of the ionic concentration in pore water, the governing equations for the ions in concrete pore solution can be expressed as:

$$
\begin{gathered}
\tau^{2} \frac{\partial}{\partial t}\left(C_{i}+S_{i}\right)=z_{i} \nabla\left[D_{i}\left(\frac{F}{R T} \nabla \phi\right) C_{i}\right]+\nabla\left(D_{i} \nabla\left(C_{i}\right)\right)-\tau \nabla\left(C_{i} v\right) \\
\frac{F}{R T} \nabla \phi=-\frac{\frac{\tau l}{F \varepsilon} \sum_{i}^{n} z_{i} D_{i} \nabla C_{i}}{\sum_{i}^{n} z_{i}^{2} D_{i} C_{i}} \\
I=\frac{\nabla \psi}{\rho_{c}} \& \quad \nabla I=0 \\
v=-D_{w} \nabla S_{w}
\end{gathered}
$$

where $\tau$ is the tortuosity of pore network, $C_{i}$ is the concentration of ionic species $i$, in concrete pore water, $t$ is time, $S_{w}$ is pore water saturation, $S_{i}$ is the concentration of ionic species in concrete solid phase but in terms of the pore water volume, $z_{i}$ is its charge number, $F$ is the Faraday's constant, $R$ is gas constant, $T$ is kelvin temperature, $\mathrm{D}_{i}$ is the diffusion coefficient of ions in pore water, $\phi$ is the local 


\section{Advanced Materials Letters www.vbripress.com/aml}

electrostatic potential in pore water and $v$ is the superficial velocity of bulk pore water in concrete, $\mathrm{n}$ is the total number of ionic species in concrete pore water. Eq. (5) is the ohm's law and local neutral electrical condition, where $I$ is the electrical current density applied externally on the concrete such as in case of cathodic protection. $\psi$ is external applied electrical potential and $\rho_{c}$ is the concrete electrical resistivity, which will be defined by Eq. (2). Eq. (6) describes pore water diffusion in concrete, $D_{w}$ is hydraulic diffusivity $[\mathbf{1 8 , 1 9 ]}$.

Eqs. (2)-(6) now are applied to simulate a bridge column standing in seawater as shown in Fig. 8. The column is exposed to repeated wetting and drying condition in tidal zone and reinforcement under cathodic protection with applied current density of $30 \mathrm{~mA} / \mathrm{m}^{2}$.
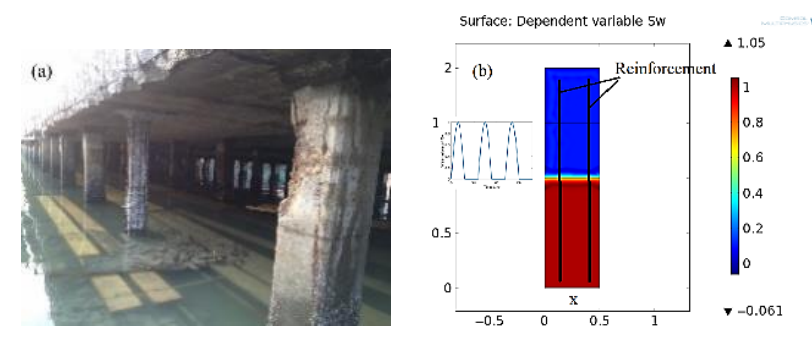

Fig. 8. (a) Columns in seawater, (b) a numerical model.

Fig. 9 shows the modelling results. It shows that the model works well, which provides a quantitative assessment for the effect of the applied CP current density to prevent chloride ingress deep into concrete to reach the position of reinforcement.

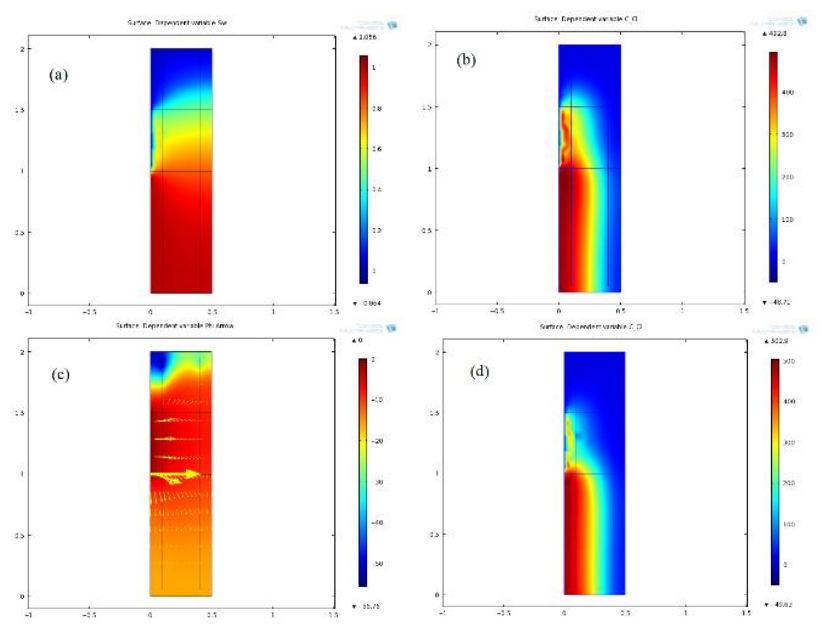

Fig. 9. Concrete condition after 1 year exposure. (a) Water saturation profile, (b) Chloride profile without CP, (c) Applied CP current distribution, (d) Chloride profile with CP.

\section{Conclusion}

This paper presents an experimental study on the effect of water and chloride content and porosity on concrete electrical resistivity. It highlights that water and chloride are two major factors influencing concrete electrical resistivity. Meanwhile the effect of porosity presents obvious when water content is expressed in terms of pore water saturation degree. A characteristic model successfully represents the relationship of the resistivity to these factors. A case study has demonstrated the use of the model in the numerical modelling for a real world application - reinforcement cathodic protection for concrete structures exposed to a typical environmental condition.

\section{Acknowledgements}

The experiment work was funded by the Iraqi Ministry of Higher Education and Scientific Research Scholarship Program.

\section{Author's contributions}

Conceived the plan: YW; Performed the expeirments: HO; Data analysis: YW, HO, NX; Wrote the paper: YW. Authors have no competing financial interests.

\section{Conflicts of interest}

There are no conflicts to declare.

\section{Keywords}

Concrete electrical resistivity, water saturation, chloride, porosity, cathodic protection modelling.

\section{Received: 21 March 2020}

Revised: 16 April 2020

Accepted: 04 May 2020

\section{References}

1. Bertolini, L.; Elsener, B.; Pedeferri, P.; Redaelli, E.; Polder, R. B. ( $2^{\text {nd }}$ Ed.); Corrosion of steel in concrete: prevention, diagnosis, repair; Wiley-VCH Verlag $\mathrm{GmbH} \& \mathrm{Co}$. KGaA, Weinheim, Germany, 2013.

2. Morris, W.; Vico, A.; Vázquez, M.; Electrochim. Acta, 2004, 49, 4447.

3. Hornbostel, K.; Larsen, C. K.; Geiker, M. R.; Cem. Concr. Compos., 2013, 39, 60 .

4. Alonso, C.; Andrade, C.; Gonzalez, J.; Cem. Concr. Res., 1988, 18 , 687.

5. Saleem, M.; Shameem, M.; Hussain, S.; Maslehuddin, M.; Constr. Build. Mater., 1996, 10, 209.

6. Villagrán Zaccardi,Y. A.; Di Maio, Á. A.; Mag. Concr. Res., 2014, 66, 484 .

7. Wilson, K.; Jawed, M.; Ngala, V.; Constr. Build. Mater., 2013, 39 , 19.

8. Qiao, G. F.; Guo, B. B.; Qu, J. P.: Instrumentation and Measurement, Computer, Communication and Control, Fifth International Conference, 2015, 836.

9. Liu, Y.; Shi, X. M.; Anti-Corros. Methods M., 2012, 59, 121.

10. Qiao, G. F.; Guo, B. B.; Ou, J. P.; Xu, F.; Li, Z. H.; Constr. Build. Mater., 2016, 119, 260.

11. Wang, Y.; Chloride Transport in Concrete: Mathematical Description and Modelling; VDM Publishing House Ltd., Riga, Latvia, 2011.

12. Hornbostel, K.; Larsen, C. K.; Geiker, M. R.; Cem. Concr. Compos., 2013, 39, 60 .

13. Layssi, H.; Ghods, P.; Alizadeh, A. R.; Salehi, M.; Concrete International-ACI, 2015, 37, 41.

14. Azarsa, P.; Gupta, R.; Adv. Mater. Sci. Eng., 2017.

15. Katwan, M. J.; PhD thesis, University of Glasgow, UK, 1988.

16. Wang, Y.; Wang, X. Y.; Scholz, M.; Ross, D. K.; Constr. Build. Mater., 2012, 35, 941.

17. Xiang, N.; Wang, Y.; Oleiwi, H. M.; Chadwick, E.; Yao, G.; Augusthus-Nelson, L.; Chen, X.; Shabalin, I.; Mag. Concr. Res., 2019.

18. Wang, Y.; Li, L-Y.; Page, C. L.; Build. Environ., 2005, 40, 1573.

19. Wang, Y.; Oleiwi, H.; Wang, C-Y.; Xiang, N.; Geng. J.; Constr. Build. Mater., 2020, 253, 119074. 